\title{
Edição e análise de fenômenos linguísticos presentes em um manuscrito eclesiástico setecentista de Minas Colônia
}

\section{Editing and analysis of linguistic phenomena present in an $18^{\text {th }}$ century ecclesiastic manuscript from colonial Minas Gerais period}

\author{
Marcus Vinícius Pereira Dores* \\ Universidade Federal de Minas Gerais, Belo Horizonte, MG, Brasil \\ Soélis Teixeira do Prado Mendes ${ }^{* *}$ \\ Universidade Federal de Ouro Preto, Ouro Preto, MG, Brasil
}

\begin{abstract}
Resumo: Neste artigo temos duplo objetivo: discutir a importância de transcrição feita com critérios filológicos e mostrar como o respeito ao texto original possibilita ao pesquisador diacronista, e ao público em geral, conhecer o uso linguístico, manifesto no manuscrito sob análise, de um estágio pretérito da língua. Na segunda parte do texto, é feita uma apresentação não exaustiva de fenômenos linguísticos extraídos de parte de um manuscrito do século XVIII, intitulado Processo De Genere Vita et Moribus de Francisco de Paula Meireles (1779).
\end{abstract}

Palavras-chave: Documento manuscrito. Edição filológica. Fenômenos linguísticos.

\begin{abstract}
This study addresses two $m$ ain issues: first, the importance of philological criteria in a transcription. Second, how the faithfulness to the original text allows the researcher to be acquainted with the language usage from a previous language stage; the language usage is manifest in the analysed manuscript. In the second part of the text, linguistic phenomena extracted from an $18^{\text {th }}$-century manuscript are briefly presented. The manuscript is entitled Processo de Genere Vita et Moribus de Francisco de Paula Meireles (1779).
\end{abstract}

Keywords: Manuscript document. Philological edition. Linguistic phenomena.

\section{INTRODUÇÃO}

Neste artigo temos duplo objetivo: discutir a importância de transcrição feita com critérios filológicos e mostrar como o respeito ao texto original possibilita ao pesquisador diacronista, e ao público em geral, conhecer o uso linguístico, manifesto no manuscrito sob análise, de um estágio pretérito da língua. O corpus utilizado faz parte do manuscrito Processo De Genere Vita et Moribus de Francisco de Paula Meireles (1779), que é parte constituinte do projeto de pesquisa, já concluído, intitulado $O$ estudo da

\footnotetext{
* Mestrando do Programa de Pós-Graduação em Estudos Linguísticos da Universidade Federal de Minas Gerais, bolsista do CNPq, Belo Horizonte, MG, Brasil; marcusdores@hotmail.com

** Professora Adjunta do Departamento de Letras do Instituto de Ciências Humanas e Sociais da Universidade Federal de Ouro Preto, Ouro Preto, MG, Brasil; soelisufop@gmail.com
} 
concordância variável (nominal e verbal) em manuscritos setecentistas e oitocentistas de Minas Colônia 1 .

O presente texto está dividido em três partes: primeiramente, discutimos sobre a contribuição dos estudos filológicos para a transcrição de documentos manuscritos, perpassando pelos tipos de edição e as normas de transcrição adotadas. Posteriormente, trataremos do gênero Processo De Genere Vita et Moribus, apontando, sobretudo, as funções social, histórica e religiosa imbricadas em Processos de Ordenação Eclesiástica. Na sequência, dada a extensão máxima deste artigo, serão apresentadas a transcrição total e o fac-símile do primeiro fólio de um dos autos (Auto de Sequestro de bens) que está contido no Processo De Genere Vita et Moribus de Francisco de Paula Meireles, de 1779. Por fim, na terceira parte, apresentaremos os fenômenos linguísticos - fônicos e morfossintáticos - sem, entretanto, apresentarmos uma análise exaustiva.

\section{A IMPORTÂNCIA DOS CRITÉRIOS FILOLÓGICOS}

De acordo com Mattos e Silva (1991, p. 15), em qualquer pesquisa de manifestações da língua em uso, o corpus sob análise deverá ser, "necessariamente, um corte intencional sobre a totalidade de uma língua; a sua data, o seu lugar e os seus informantes serão identificados e definidos". Entretanto, prossegue a autora, quando a análise se refere a um estado da língua já passado, o corpus no qual a pesquisa se apoiará já está constituído. Assim, caberá ao linguista-pesquisador que deseja estudar um uso linguístico anterior ao presente, determinar "os limites do seu campo de observação sobre documentação preexistente", já que, conforme Mendes (2008, p. 14), "não existe outra forma de se pesquisar uma língua pretérita que não seja através de textos escritos". Assim, no caso da pesquisa desenvolvida, o limite do campo de atuação circunscreve-se ao período da língua portuguesa escrita no Brasil cujos documentos datam da segunda metade do século XVIII, como é o caso deste que será tratado no presente artigo, à primeira metade do século XIX.

Uma vez determinada a época a que se referem os documentos, deve ser estabelecida, por meio da Crítica Textual, a gênese dos textos. Conforme Spina (1994, p. 94), tendo em vista a especificidade dos textos pertencentes à cultura ocidental, "cuja tradição tem como baliza a aparição da imprensa no século XV", a Edótica (ou Crítica Textual) pode ser periodizada em quatro momentos: clássica - aplicada aos textos clássicos, gregos e latinos, até o fim do período helenístico e da baixa latinidade; medieval - aplicada aos códices pertencentes à Alta e Baixa Idade Média; moderna - aplicada ao texto impresso, desde os primeiros até os textos do século XIX; e a contemporânea. Muito embora o corpus da presente pesquisa refira-se ao período moderno da nossa história e, portanto, pertencente à época pós-imprensa, como aponta o autor ora citado, o documento sob análise é manuscrito e foi exarado por um escrivão da vara eclesiástica do Arraial do Tejuco, Antonio Dias Braga, em 1779.

Mas, em que pese a época em que foi escrito o texto, precisamos levar em conta que o objetivo da Edótica é o mesmo: "estabelecer um texto que se avizinhe o mais possível do original, tendo em vista a sua publicação". (Spina, 1994, p. 94).

\footnotetext{
${ }^{1}$ Pesquisa desenvolvida pelos autores com apoio finaneiro do CNPq (proceso 129043/2016-8).
} 
O diacronista que pretende levantar e transcrever manuscritos para compor seu corpus de pesquisa deve possuir conhecimentos de Filologia, uma vez que o resultado de seu trabalho deve refletir fielmente o testemunho transcrito. Para que isso ocorra, conforme Fachin (2008, p. 19), deve fazer uso de "normas de transcrição e critérios de leitura elaborados, com o intuito de editar os documentos de forma fidedigna, ou seja, sem oscilações". Para além dessas questões, prossegue o autor, "para que o resultado de sua edição possa ser examinado por outros pesquisadores, todos os critérios utilizados devem ser divulgados" (Fachin, 2008, p. 19).

Uma vez estabelecida uma edição que seja a mais fiel possível ao texto original, o levantamento e a análise propostos para os fenômenos linguísticos encontrados no corpus selecionado terão maior credibilidade. Isso porque há que se considerar que, na pesquisa diacrônica, diferentemente da sincrônica atual, não possuímos falantes que possam servir de contraponto aos dados levantados; daí a importância do rigor filológico no momento da transcrição de testemunhos de um estágio pretérito da língua. A seguir, trataremos dos tipos existentes de edição.

\section{TIPOS DE EDIÇÃO}

A edição de textos antigos tem um papel histórico-cultural diretamente ligado à propagação da memória de certos grupos entre distintos públicos - dos mais leigos aos mais versados - dependendo da modalidade de edição adotada. O processo de edição assume também o papel de perpetuação, contribuindo para a preservação do suporte material que contém o texto manuscrito, ou seja, à medida que a circulação do texto editado se dá de forma mais abrangente e acessível, pode-se abrir mão da consulta ao original. Por isso, a necessidade de se fazer um trabalho reto, embasado em normas claras que sejam seguidas fielmente.

Segundo Spina (1994, p. 77-79), existem diversas maneiras de se editar um texto: a edição fac-similar ou mecânica, a diplomática, a semidiplomática ou paleográfica e a edição crítica. A opção por uma ou mais de uma dessas edições recairá sobre qual o público almejado, pois dificilmente uma mesma edição pode ser adequada a públicos distintos. (cf. Cambraia, 2005)

No presente artigo, vamos apresentar a edição fac-similar e a diplomática do manuscrito sob análise. No primeiro tipo há um grau zero de mediação, já que apenas ocorre a reprodução mecânica de um testemunho através de meios mecânicos, fotografia, xerografia, escaneamento, microfilmagem etc. Vale destacar que essa afirmação não leva em consideração as alterações que os instrumentos de reprodução de imagem - escâner, câmera fotográfica, etc. - podem conferir à cópia. Já o segundo tipo de edição tem por objetivo principal transcrever em caracteres da imprensa moderna as escritas antigas, procurando interferir o mínimo possível no documento. Embora seja destinada ao público científico, é um tipo de edição bastante adotado, pois possui baixo grau de mediação e a transcrição é rigorosamente conservadora justamente porque são mantidos os sinais abreviativos, de pontuação, paragrafação, translineação, além de não serem desfeitas as fronteiras de palavras. Nesse tipo de edição, o leitor é poupado da árdua tarefa de decifrar as formas gráficas da escrita original, o que é uma vantagem, sobretudo para aqueles com menor prática de leitura de manuscritos antigos. Para o estudo da história da língua, a edição diplomática mostra-se bastante eficiente; isso porque é possível, por meio de fontes de programas 
de textos, fazer uma reprodução bastante rigorosa do passado. No entanto, não se pode perder de vista que, não obstante todo o cuidado por parte do editor, "uma edição diplomática já constitui uma interpretação subjetiva, pois deriva da leitura que um especialista faz do modelo". (Cambraia, 2005, p. 94)

Conforme se discutiu anteriormente, é necessário que sejam adotados critérios bem elaborados para o reconhecimento e identificação de caracteres, de forma que o texto original seja respeitado, dentre outros aspectos filológicos de edição. Para tanto, normas devem ser propostas e seguidas à medida que o trabalho de transcrição é realizado. A seguir, apresentaremos as normas adotadas para a transcrição do manuscrito sob análise.

\section{NORMAS DE TRANSCRIÇÃO}

As normas adotadas para a transcrição do documento tiveram como base o modelo adotado por Mendes (2008) que, por sua vez, baseou-se em Cambraia et al. (2001).

a) A transcrição procurará ser fiel ao texto original;

b) Não serão desdobradas as abreviaturas²;

c) Não será estabelecida fronteira de palavras que venham escritas juntas nem se introduzirá hífen ou apóstrofo onde não houver; Ex: "deNosso"; "deJulho"; "emvirtude";

d) Serão mantidas a pontuação e acentuação originais;

e) Será respeitado o emprego de maiúsculas e minúsculas como se apresentam no original;

f) Quando a leitura paleográfica de uma palavra for duvidosa, a sua transcrição será feita entre parênteses: ( );

g) São transcritos na sua forma original os numerais, tanto indo-arábicos como romanos;

h) Serão apontadas antes da transcrição as intervenções de terceiros no documento original, bem como o seu estado de conservação;

i) Serão informadas em nota as anotações de outro punho, as alterações e os borrões de tinta;

j) Serão transcritos como pontos dentro de colchetes precedidos pela cruz $†$ (sendo que o número de pontos é o de caracteres não legíveis) (cf. Cambraia, 2005, p. 128) os caracteres cuja leitura for impossível. Entretanto, quando não for possível identificar esse número, apenas será registrada a cruz;

k) Palavra(s) danificada(s) por corrosão de tinta, umidade, rasgaduras ou corroídas por insetos ou outros será(ão) indicada(s) entre colchetes, assim: [corroída] ou [corroídas]. Em se tratando de um trecho de maior extensão danificado pelo mesmo motivo será indicada entre colchetes a expressão [corroída + de 1 linha];

1) A divisão das linhas do documento original será preservada, ao longo do texto, na edição, pela marca de uma barra vertical: | entre as linhas. A mudança de fólio será indicada com duas barras verticais: ||;

m) As páginas serão numeradas de acordo com o documento original, indicadas, nesse caso, entre duas barras verticais, além de apresentar o estado do fólio. Exemplos: | fl.1r. ||; || fl.1 v. ||;

\footnotetext{
${ }^{2}$ Fizemos a opção pelo não desdobramento das abreviaturas, por reconhecer que se trata de registros linguísticos que necessitam de uma atenção especial, a qual não será tratada neste trabalho.
} 
n) Se o original não for numerado ou estiver ilegível sua numeração, os números acrescentados serão impressos entre colchetes, indicando-lhes o estado do fólio. Exemplos: [fl.1 r.]; [fl.1v.];

o) $\mathrm{Na}$ edição, as linhas serão numeradas de $5 \mathrm{em} 5$ a partir da quinta, considerando, inclusive, o título. Essa numeração será colocada à margem direita da mancha, à esquerda do leitor. Será feita de maneira contínua por documento.

p) As assinaturas simples ou as rubricas do punho de quem assina serão sublinhadas. Já aquelas marcadas com um $\mathrm{X}$, além de se apresentarem sublinhadas, serão marcadas pelo tipo itálico. Exemplos: "Joaquim Pinto" e De Fructuoso + Pra. de Souza|;

q) Os espaços em branco deixados pelo escrivão serão assim identificados: [espaço];

r) Os fragmentos de frases ou palavras que foram suprimidos pelo escrivão serão indicados em nota.

\section{A HabilitaÇão DE GENERE VITA ET MoribuS}

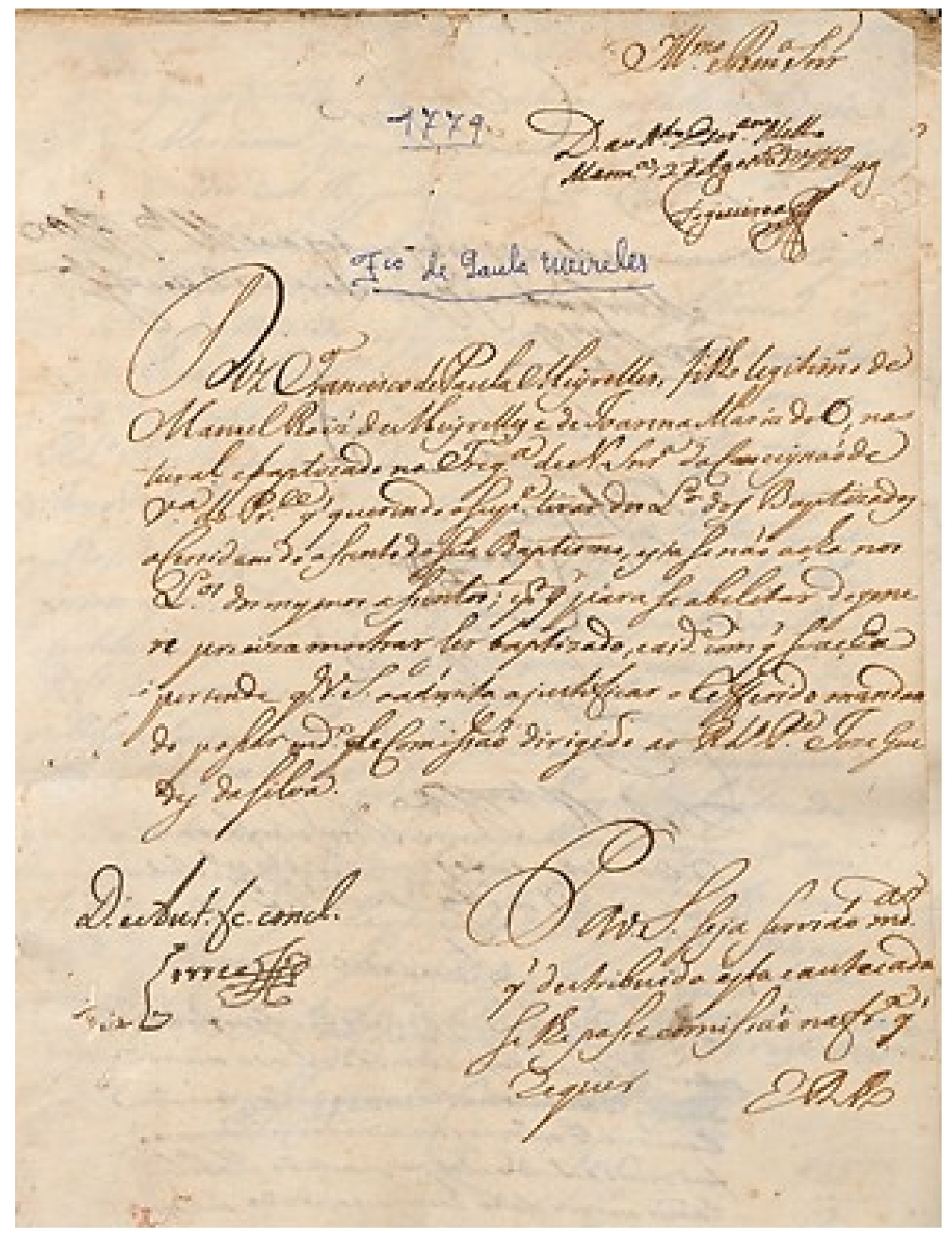

Fonte: Arquivo Eclesiástico da Arquidiocese de Mariana.

Figura 1 - Edição fac-similar do primeiro fólio do manuscrito.

Pela tradição, que se manifesta principalmente pelos ritos litúrgicos e pelo costume da Igreja Católica, tanto Oriental como Ocidental, sabe-se que o sacramento 
da ordem - dividido em três graus: o episcopado, o presbiterado e o diaconato - é destinado àquelas pessoas que desejam ingressar na vida sacerdotal.

O Catecismo da Igreja Católica (1998, p. 1549, apud Lumen Gentium, 1964) define que "[p]elo ministério ordenado [...] a presença de Cristo como chefe da Igreja se torna visível no meio da comunidade dos fiéis". Por toda essa importância religiosa, o sacramento da ordem só pode ser recebido, ao que se pressupõe pelo documento, por aqueles escolhidos por Deus e ratificados pela Igreja.

Conforme se sabe, a Inquisição forçou judeus e mouros a professarem a fé no cristianismo e, ao mesmo tempo, criou-lhes uma barreira intransponível, pois os novos cristãos $^{3}$ estavam marcados pelo pecado da sua origem. Em muitas ocasiões, era exigida limpeza de sangue, sobretudo para assumir encargos religiosos. Justamente para evitar a atribuição de cargos aos novos cristãos, todos os candidatos às ordens sacras eram submetidos à investigação genealógica.

A partir do século XVI, com a promulgação do Breve De puritate sanguinis, do papa Urbano VIII, para assumir qualquer grau religioso, todos os candidatos deveriam submeter-se aos processos de habilitação De Genere, vita et moribus (genealogia, vida e costumes), por meio dos quais comprovavam-se a "pureza de sangue e costumes" e a existência de uma renda mínima. (cf. Villalta, 2007).

\begin{abstract}
[Os] processos de ordenações, mais conhecidos em linguagem eclesiástica como 'De Genere et Moribus', reúnem investigações com relação à procedência, idoneidade e conduta moral do pretendente às ordens sacras e ao presbiterado. Comportam três autos: 'de genere', em que são levantados dados referentes à identidade, filiação, naturalidade, fé católica do candidato; 'de vita et moribus', em que se fazem diligências, com a tomada de depoimentos juramentados, sobre os costumes e condição moral do futuro clérigo; 'de patrimônio', que recolhe provas e títulos de ordem financeiro-econômica, assegurando que o ordinando não era pessoa desvalida - uma norma de prudência bem conveniente a uma época em que clérigos percebiam uma côngrua dos cofres públicos, devendo, então, serem impedidos os oportunistas e interesseiros ${ }^{4}$.
\end{abstract}

Os processos para ingresso à vida sacerdotal eram demorados, justamente porque exigiam testemunhos e comprovações de diversas pessoas. Ao final, os candidatos que passavam por esse rigoroso processo eclesiástico dividiam as honras com os seus familiares. "As famílias, durante o Período Colonial, mantiveram a prática de encaminhar ao menos um de seus filhos ao sacerdócio, que se apresentava como uma carreira almejada [...] para os que provinham das "boas famílias"' (Villalta apud Wernet, 2007, p. 28). Ter entre os seus familiares pelo menos um sacerdote com a declaração de boas origens era um glorioso status social. Segundo Carneiro (2005), a distinção entre cristãos-novos e cristãos-velhos persistiu até 1773, quando o marquês de Pombal a aboliu, por decreto. Mesmo assim, por muitos anos continuou o temor de que alguma pessoa de sangue "impuro" se habilitasse ao sacerdócio.

Conforme mencionado anteriormente, o manuscrito que é objeto de análise, neste artigo, denominado Auto de Sucreto, é parte constituinte do processo de ordenação

\footnotetext{
3 Novos cristãos, cristãos novos, ou marranos: termos utilizados para designar pessoas recémconvertidas ao cristianismo ou pessoas descendentes de judeus ou de outra estirpe.

4 Nota Explicativa do Catálogo de Processos de Ordenações, Apresentação e Oposição. Arquivo Eclesiástico da Arquidiocese de Mariana - AEAM. Mariana, MG, 2012, s/p.
} 
De Genere Vita et Moribus, do candidato Francisco de Paula Meireles. O processo, em sua totalidade, possui 195 fólios organizados em 4 maços; a parte que aqui analisamos está contida no último maço e possui 5 fólios (fólios 9 a 11, do maço 4), entre recto e verso. A seguir apresentaremos a edição fac-símile do primeiro fólio do manuscrito sob análise, seguida de sua edição diplomática.

\section{APRESENTAÇÃO DO CORPUS: EDIÇÃO FAC-SÍMILE E DIPLOMÁTICA}

Metodologicamente, todos os fólios de que é composto o processo foram digitalizados e, para facilitar a leitura, uma vez que alguns trechos estão ilegíveis, foi utilizado o software Photoshop para o tratamento das imagens. Já para a edição diplomática, após várias leituras do testemunho, foi proposto o alfabeto do documento, que, conforme Fachin (2008, p. 45), "representa etapa essencial para a leitura e transcrição satisfatórias de qualquer manuscrito, principalmente quando se trata de grafia de difícil decifração.” Em seguida, com base nas normas já estabelecidas, procedeu-se à transcrição.

A seguir apresentamos a ficha codicológica que contém informações referentes à localização do documento, de que material é feito e como é composto, além de informações sobre a escrita.

Quadro 1 - Ficha codicológica

\begin{tabular}{|c|c|}
\hline Cota & $\begin{array}{l}\text { Arquivo Eclesiástico da Arquidiocese de Mariana (AEAM) - Cúria } \\
\text { Metropolitana; Armário 04; Pasta N } 604,4^{\circ} \text { maço, fl. } 9 \text { v. }\end{array}$ \\
\hline Documento & Processo de Genere Vita et Moribus de Francisco de Paula Meireles. \\
\hline Assunto & $\begin{array}{l}\text { Análise da vida, da genealogia e do comportamento do candidato ao } \\
\text { sacerdócio, Francisco de Paula Meireles. }\end{array}$ \\
\hline Datação & 1779. \\
\hline Local & Arraial do Tejuco (atual Diamantina - MG). \\
\hline Suporte material & Cartáceo, sem pauta e sem marca d'água. \\
\hline Composição & $\begin{array}{l}195 \text { fólios com dimensão de } 350 \text { mm x } 230 \text { mm, aproximadamente. A } \\
\text { dimensão é imprecisa, em função da deterioração das margens. }\end{array}$ \\
\hline $\begin{array}{l}\text { Organização da } \\
\text { página }\end{array}$ & $\begin{array}{l}\text { Nem todos os fólios encontram-se numerados. Conforme a contagem } \\
\text { dos fólios que compõem o documento, o "Auto de Sequestro", } \\
\text { composto de } 5 \text { fólios, encontra-se no } 4 .^{\circ} \text { maço do processo. }\end{array}$ \\
\hline $\begin{array}{l}\text { Intervenção de } \\
\quad \text { terceiros }\end{array}$ & $\begin{array}{l}\text { Há algumas pequenas marcações feitas a lápis na margem direita do } \\
\text { documento. }\end{array}$ \\
\hline $\begin{array}{l}\text { Estado do } \\
\text { documento }\end{array}$ & $\begin{array}{l}\text { Bordas parcialmente deterioradas pela ação de papirófagos, o que } \\
\text { impossibilita a identificação de alguns grafemas; ocorrência de } \\
\text { opistografia, que, por sua vez, não inviabiliza a leitura do documento; } \\
\text { presença de corrosão causada por compostos químicos presentes na } \\
\text { tinta utilizada para escrita. }\end{array}$ \\
\hline
\end{tabular}


Com relação à $\quad$ Escrita levemente inclinada para direita, com exceção da letra 'd' (de escrita tipo uncial).

Com relação aos As letras maiúsculas, em geral, são de fácil identificação, mesmo grafemas apresentando certa variação; em alguns contextos, as letras 'a', 'e' e 'o' podem ser confundidas entre si; as letras 'e' e 'i' são facilmente confundidas; adotou-se, para fins de transcrição, o pingo como marca de diferenciação entre essas duas letras.

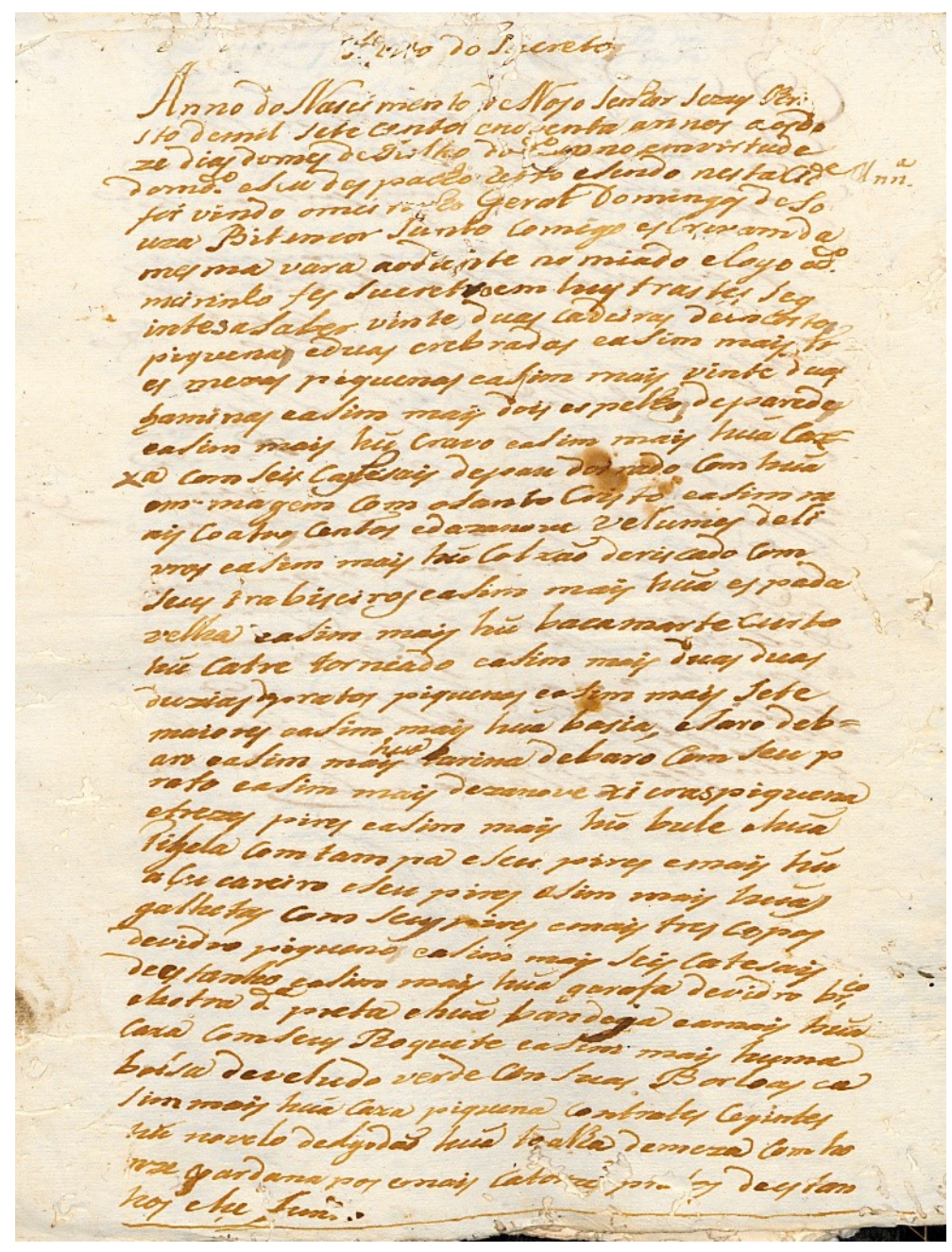

Fonte: Arquivo Eclesiástico da Arquidiocese de Mariana.

Figura 2 - Edição fac-similar do fl. 9v, 4. ${ }^{\circ}$ maço.

Conforme já se discutiu, apenas apresentaremos o fac-símile do fl. $9 \mathrm{v}$ do manuscrito que ora analisamos por questões de espaço, mas a transcrição refere-se a todos os 05 fólios do Auto de Sucreto, que faz parte do Processo de Genere Vita et Moribus de Francisco de Paula Meireles. 


\author{
Transcrição dos fólios 9v. a 11v. do Auto de Sucreto \\ presente no Processo De Genere Vita et Moribus de Francisco de Paula Meireles.
}

| fl.9v.|| Ato do S[†..]creto | Anno do Nascimento deNoso Senhor Jezus Cri | sto demil sete centos enoventa annos aosdo $\mid$ ze dias domes deJulho $\left(\operatorname{dod}^{\circ}\right)$ anno emvirtude | domd. ${ }^{\circ}$ es (se) des pacho vito esendo nes tacideMnn. ${ }^{\text {a }}{ }^{5}$ | foi vindo ornci r[†..]ho GeralDomingos deSo | uza Bitencor Junto Comigo escrevam da | mesma vara

5 aodiante no miado elogo ad. ${ }^{\circ} \mid$ meirinho fez sucretro em hus tras tes seg | intes asaber vinte duas cadeiras de(e)ncostar | piquena eduas crebradas easim mais tr | es mezas piquenas easim mais vinte duas | laminas easim mais dois espelhos deparede | easim mais hũ cravo easim mais huã Cax | xa com seis castesais depau doirado com huã | em[t.]magem com osanto Cristo easim m | ais coatro centos edazanove velumes deli |

10 vros easim mais hũ colxão deriscado com | seus trabiseiros easim mais huã espada | velha easim mais hũ bacamarte curto | hũ catre torniado easim mais duas duas | duzias depratos piquenos easim mais sete $\mid$ maiores easim mais huã basia ejaro deb $=\mid$ aro easim mais hua ${ }^{6}$ tarina de baro com seu p | rato easim mais dezanove xi cras piquena | etrezes pires easim mais hũ bule e huã | tilgela com tampa e seus pires emais hũ | açucareiro

15 eseu pires easim mais huãs | galhetas com seus pires emais tres copos | devidro piqueno easim mais seis catesais | de estanho easim mais huã garafa devidro bro | ehotra d. ${ }^{\mathrm{a}}$ preta ehuã bandeja eamais huã | caxa comseus Roquete easim mais huma | bolsa develudo verde con suas Borloas ea $\mid$ sim mais huã caxa piquena contrates cegintes $\mid$ hũ novelo dealgodaõ huã toalha demeza com ho | nze coardanapos emais catorze pr(at)os

20 deestan | hos ehu fundo ||

| fl.10r.|| ehuã panelinha debaro piquena ehuã fronha | depano liza eapiquena com seus papeis tres | xicras edois pires ehuã tigela com seu prato | emais dous pires emais hua faca decabo de | prata antiga emais hum(a) colher egarfo de | prata huma bandeija pequena emais huã | (f)olha detabaco emais huã balança demeia | livra co(m) seu marco

25 easim mais huã navalha | com folha deobreia easim mais hũ fexo dees | pingarda easim mais huma Justificaçaõ | deBautismo easim mais humas fivellas | delCas tinha de sapato ehuma chave convarios | papeis emais hũ catisal devidro deparede | edois baretes velho s emais huã lamina toda | doirada emais coatro camizas finas easim mais | d[†..]es (Pe)ntiadores emais hũs corteanados depano | delinho aberto emais dois lançoies e huã

30 Colxa de | xita emais duas toalhas demam humadepano delinho hotra deAlgudaõ e mais dois fraques | dexitas curtos com os Jalecos hũ Calcaõ de | xita ehũ lenco dexita easim mais hũ vestido | enteiro deseda Roxa eassim mais huã Batinha | ecapa degala preta easim mais hũ tinteiro de | pedra easim mais hua Batinha ecapa de seti $\mid$ n emais hũ vestido evestia develudo Roxo emais | hotro vestido de setin preto emais hũ Calcaõ

35 develudo cor decanela emais hũ fraque curto | de(dasrante) Branco com seus Jaleco do mesmo | emais hũ par demeias pretas desedas com | pes rotas ema(i)s humas tiras depano ||

| fl.10v. || (escarlate) reco[t.]ta[t.] as easim mais hüma | vestia ecalcaõ de setin preto lavrado ehu | ma vestia degala preta ehotra dita depano | roxo easim mais huã tigela com

40 remedio | deButica emais tres pares desapatosvelho | easim mais hũ Bodoque ehũ par decape | ladas sem xarel emais tres estantes e huã | escova devestido emais duas $\mathrm{p}^{7}$ aetas huã | velha ehotra nova emais hũ Baul emais huã | colxa desarafina emais hũ traviseiro velho emais | dozes livros ehũ carderno ehuã escova ecoatro | laminas emais digo velha equebradas emais hũ | espriguiseiro e hũ esxarga[†..] emais huã me | za e mais hũ Balaio

45 corberto decezero emais | hũ Baril degoa emais huma xecolateira ehua | Banca emais hũ maxadinho emais duas gamelas | e hũ Moleque por nomeDavi nasam Mina | emais hũa meza comsua Gaveta com varios | papeis emais hũ pratro Grande deestanho mais | dois

\footnotetext{
${ }^{5}$ Não há separação de fronteira entre as duas abreviaturas que, por sua vez, adentram a margem direita do documento.

${ }^{6}$ No documento, esta palavra está escrita acima da anterior, a saber, 'mais'.

${ }^{7}$ No manuscrito há uma sobreposição de grafemas: 'p' e 'b’.
} 
piquenosdeestanho mais (outro) pratro Gra | nde delousa emais hua Basia deestanho hũ | (zada) emais hua Supera comtanpa emais | dois pires ehũa (cor)besa desipo emais hũ |

50 candeeiro delataõ emais hũ catre lizo dep | au emais sete tamboretes emais hua farda | depano azul ecamizas ehua Gravata dexita | Branca ehũ par defivela amarela deseu | muleque emais coatro tanborete emais acadera $\mid$ aonde ensinav ${ }^{8}$ a os seus estudos emais hũ Bu | neco vestido desetin verde emais huã $\mathrm{B}^{9}$ oseta deta $\mid$ tarubo duas pedras lapidadas Emais huãCamiza | deMulher emais sete Chaves dea Br[†..] portas | emais huã sinta

55 detafeta Cramezim velha emais | huma sela hũ freio est [†]depicaria deferro ||

| |fl. 11r.|| emais huma Reide ao [corroido] sederme emais hũ | (par) decanba digo decasamba emais hũ par | desapato com fivelas deprata piquenas emais | huã trempe deduas panelas emais huã can | deia deferro emais hũ (tan)burete emais huã | lamina piquena deSam Fran ${ }^{\text {co }}$ emais varios p | apeis que a Charo dentro dagaveta emais huma

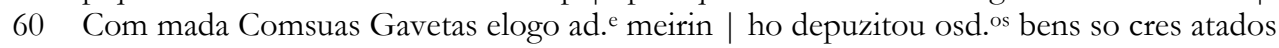
emmão | epoder doCap..$^{a m}$ Manoel Bras Fr. ${ }^{a} \tilde{\mathbf{q}}$ deles seodeo | porentregue eseo bregoce asleis defiel depuzita | răo eeu escrivam digo q Renunciava Juizo | doseu foro [corroido]

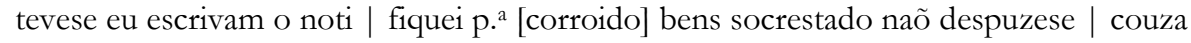

65 (A)lguma sem especial ordem deste Juizo | penna dalei edetudo Como seobregou fis este | auto desucrestos eñ̃ asignou aqui Junto | Com omeirinho Geral eeu escrivamda | mesma vara q̃ escrives An. ${ }^{\text {to Dias Braga } \mid \text { Manoel Bras Pereira daS Leal }}{ }^{10} \mid$ O meirinho Geral | Domingos deSousa Bitancor | Auto deaberturea | Anno doNascimento deNoso Senhor Jezus | Christo demil esete centos enoventa annos aos | doze dias domes deJulho 70 dad. ${ }^{\circ}$ anno emvirtude $\mid$ dad. $^{\circ}$ mand. ${ }^{\circ}$ eseu despacho retro do $\mathrm{M}^{\text {to }} \mathrm{Rd} \mathrm{d}^{\circ} \mid \mathrm{D}^{\text {or }}$ Vegario Geral esendo nestaCide fomos $\mid$ as cazas donde morava oP. ${ }^{\mathrm{e}}$ Mestre Fra $\mid \mathrm{n}^{\mathrm{co}} \mathrm{dePaula}$ oCal não achemos encaza ep | edindo as chaves dad. ${ }^{a}$ cazas apesoa $\tilde{\text { q }}$ (nela) | estava m(o)rando nos deo chaves de algumas ||

| fl.11v.|| dealgumas port[†] edas [†..]tras dese q̃ não | sa(bi)a ep(or) senaõ acharem $\mathrm{ch}^{11}$ aves $\mathrm{da}(\mathrm{s}) \mid$ portes egavetas eabriram co achaves de | conselho como nos mandava omd. ${ }^{\circ}$ Junto | acol abrimento $[\dagger]$ d. ${ }^{a}$ portas egavetas | eabreram avesta das testemunhas $\mathrm{aBa} \mid[\dagger .$.$] o asignadas que perzensiava \mathrm{d}^{12}$ ego que per $\mid$ zensiaram ad. ${ }^{\mathrm{a}}$ ebertura deportas egavetas $\tilde{\mathrm{q}}$ perzensiaram ad. ${ }^{\mathrm{a}}$ abrimentos deporta | esucrostos $\tilde{\mathrm{q}}$ fes nasd ${ }^{\text {os }}$ bem seu pastado | fis este termo deabrimentos enq $\operatorname{asig}^{\mathrm{n} a} \mid$ ram asd $^{\text {as }}$ testemunha Junto com omei

80 | rinho Geral eeu An. ${ }^{\text {to }}$ (Dias) Braga escrivam damesma vara q̃ [corroido] | M. .l $^{\mathrm{e}}$ [corroido] | NarcizoGomis Jaxmo13 $\mid$ Joaquim Pinto $\operatorname{Pr}^{\text {ass }} \mid$

Escrevaõ

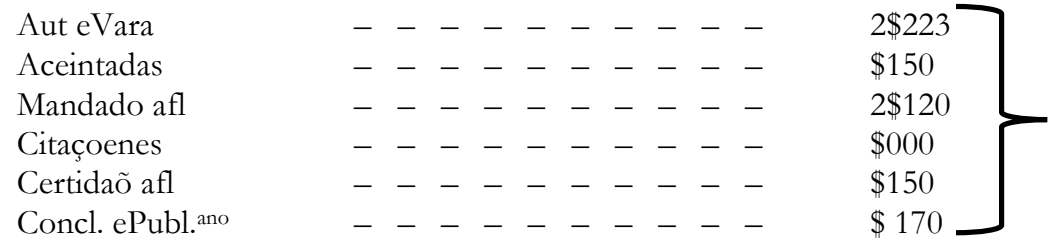

Marianna $\underline{6}$ de Julho de 1794 na

$\underline{\text { BotelE }^{14}}$

\footnotetext{
${ }^{8}$ No manuscrito há uma sobreposição de grafemas: 'd' e 'v'.

${ }^{9}$ No manuscrito há uma sobreposição de grafemas: 'p' e 'b'.

${ }^{10}$ Há um sinal público que acompanha a assinatura. registro neste mesmo documento.

${ }^{12}$ No manuscrito há uma sobreposição de grafemas: 'd' e 'q'.

${ }^{13}$ Há um sinal público que acompanha a assinatura.

${ }^{14}$ Há um sinal público que acompanha a assinatura.
}

${ }^{11}$ Há uma sobreposição de grafemas $(x$ e $c h)$ no original. O escrivão grafou a palavra chave com $x$ ou $c h$ e depois fez uma rasura. Optou-se em transcrever a palavra com $c h$ devido a ocorrências prévias desse 


\section{APRESENTAÇÃO DOS DADOS}

A seleção desses dados baseou-se, nesse primeiro momento, no "estranhamento" que estruturas de um estágio passado da língua causam em falantes/leitores contemporâneos. Conforme Tarallo (1990, p. 21, grifos nossos), "alguns segmentos [...] podem parecer à primeira vista, totalmente estranhos e irreconhecíveis de tal forma que um leitor contemporâneo poderia atribuir a eles valores estranhos". Em seguida, fizemos um levantamento de fenômenos fônicos que possuem características em comum e o mesmo foi feito com os fenômenos morfossintáticos. Há que se considerar, no entanto, que, em função de espaço, fizemos uma análise atomística dos dados, sem nos basearmos em algum modelo teórico para explicar cada ocorrência.

\subsection{Fenômenos fônicos}

Reunimos nesta subseção palavras que apresentam características comuns conforme o metaplasmo correspondente. Metaplasmos, segundo Coutinho (1962, p. 166), "são modificações fonéticas que sofrem as palavras na sua evolução", ou seja, é o nome dado à mudança ocorrida na estrutura da palavra, seja ela em função de acréscimo, subtração ou deslocamento de segmentos sonoros, representada por grafemas, de que a palavra é composta.

No quadro a seguir, apresentamos os metaplasmos localizados no manuscrito ${ }^{15}$ sob análise. As definições apresentadas são baseadas em Bisol (1981), Carvalho \& Nascimento (1969), Coutinho (1962) e Williams (1994).

15 Embora uma mesma palavra possa ter sofrido mais de um processo de mudança, apenas apresentaremos um deles. 
Quadro 2 - Fenômenos fônicos.

\begin{tabular}{|c|c|c|c|}
\hline Metaplasmos & $\begin{array}{l}\text { Número de } \\
\text { ocorrências }{ }^{16}\end{array}$ & Localização & Observações \\
\hline $\begin{array}{l}\text { Vocalização: transformação } \\
\text { de som consonantal em som } \\
\text { vocálico. }\end{array}$ & Bautismo & Linha 26 & De: baptismo \\
\hline $\begin{array}{l}\text { Epetênse: acréscimo de um } \\
\text { segmento sonoro no meio da } \\
\text { palavra. }\end{array}$ & $\begin{array}{c}\text { corberto } \\
\text { crebradas } \\
\text { pratro (2) } \\
\text { lançoies } \\
\text { Reide } \\
\text { sucretro } \\
\text { tilgela }\end{array}$ & $\begin{array}{c}\text { Linha } 50 \\
\text { Linha } 6 \\
\text { Linha } 47 \\
\text { Linha } 29 \\
\text { Linha } 56 \\
\text { Linha } 5 \\
\text { Linha } 14 \\
\end{array}$ & $\begin{array}{l}\text { Ditongação } \\
\text { Variação única: tilgela / tigela }\end{array}$ \\
\hline $\begin{array}{l}\text { Paragoge: acréscimo de um } \\
\text { segmento sonoro no final da } \\
\text { palavra. }\end{array}$ & Baul & Linha 42 & \\
\hline $\begin{array}{l}\text { Metátese: transposição de um } \\
\text { segmento sonoro na mesma } \\
\text { sílaba. }\end{array}$ & perzensiava (2) & Linha 77 & \\
\hline $\begin{array}{l}\text { Hipértese: transposição de um } \\
\text { segmento sonoro de uma } \\
\text { sílaba para outra. }\end{array}$ & socrestado (3) & Linha 64 & \\
\hline \multirow{2}{*}{$\begin{array}{l}\text { Sincope: supressão de um } \\
\text { segmento sonoro no meio da } \\
\text { palavra }\end{array}$} & $\begin{array}{l}x i \underline{\text { cras }}(2) \\
\text { catesais (1) }\end{array}$ & $\begin{array}{l}\text { Linha } 13 \\
\text { Linha } 16\end{array}$ & $\begin{array}{l}\text { Variação única: castesais/ catesais/ } \\
\text { catisal }\end{array}$ \\
\hline & $\begin{array}{l}\text { caxa (2) } \\
\text { hotro (3) }\end{array}$ & $\left.\begin{array}{l}\text { Linha } 17 \\
\text { Linha } 34\end{array}\right]$ & Monotongação. \\
\hline $\begin{array}{l}\text { Ensurdecimento (fortalecimento): } \\
\text { transformação de uma } \\
\text { consoante sonora numa } \\
\text { consoante surda homorgânica. }\end{array}$ & coardanapos & Linha 19 & \\
\hline $\begin{array}{l}\text { Enfraquecimento: nos casos, } \\
\text { transformação de uma } \\
\text { consoante oclusiva numa } \\
\text { fricativa. }\end{array}$ & trabiseiros ${ }^{17}$ & Linha 10 & Variação única: trabiseiros/traviseiro \\
\hline $\begin{array}{l}\text { Alçamento ou abaixamento: } \\
\text { mudança de uma vogal em } \\
\text { determinada altura para uma } \\
\text { vogal em mesma posição } \\
\text { (anterior ou posterior) em uma } \\
\text { altura mais alta ou mais baixa, } \\
\text { respectivamente. }\end{array}$ & $\begin{array}{c}\text { no míado } \\
\text { piqquena }(10)^{18} \\
\text { torniado } \\
\text { Bunneco } \\
\text { muleque } \\
\text { enteiro } \\
\text { Bútica } \\
\text { depuzitou }(\mathrm{x} 1)^{*}\end{array}$ & $\begin{array}{l}\text { Linha } 5 \\
\text { Linha } 6 \\
\text { Linha } 11 \\
\text { Linha } 53 \\
\text { Linha } 52 \\
\text { Linha } 32 \\
\text { Linha } 40 \\
\text { Linha } 60\end{array}$ & Abaixamento \\
\hline
\end{tabular}

${ }^{16} \mathrm{O}$ número entre parênteses refere-se ao número de ocorrências da palavra no testemunho.

${ }^{17}$ Nesse caso houve um abrandamento, classificado como degeneração (/b/ > /v/).

18 Segundo Bisol (1981, p. 259), nesses casos ocorre uma harmonização vocálica, que é “um processo de assimilação regressiva desencadeado pela vogal alta da sílaba imediatamente subsequente, independentemente de sua tonicidade - que pode se estender a uma ou mais vogais médias do ambiente." O mesmo vale para o exemplo da linha 60, depuzitou. 


\subsection{Fenômenos morfossintáticos}

Quadro 3 - Fenômenos morfossintáticos.

\begin{tabular}{|c|c|c|c|}
\hline Tipo & Ocorrência & Localização & Observações \\
\hline $\begin{array}{l}\text { Cliticização de pronomes: } \\
\text { é a aglutinação do } \\
\text { pronome, que é }\end{array}$ & ... $\tilde{\mathrm{q}}$ deles seodeo | porentregue... & Linha 61 & \\
\hline $\begin{array}{c}\text { fonicamente menos } \\
\text { saliente, a uma palavra } \\
\text { base. }\end{array}$ & ... eseo bregou asleis ... & Linhas 61-62 & \\
\hline
\end{tabular}

... en escrivam o noti fiquei... L Linha 64

Colocação pronominal $\quad$... Como seobregou fis este... $\quad$ Linha 65

(próclise): pronome

anteposto ao verbo

... estava $m(0)$ rando nos deo chaves de Linhas 72-73

algumas...

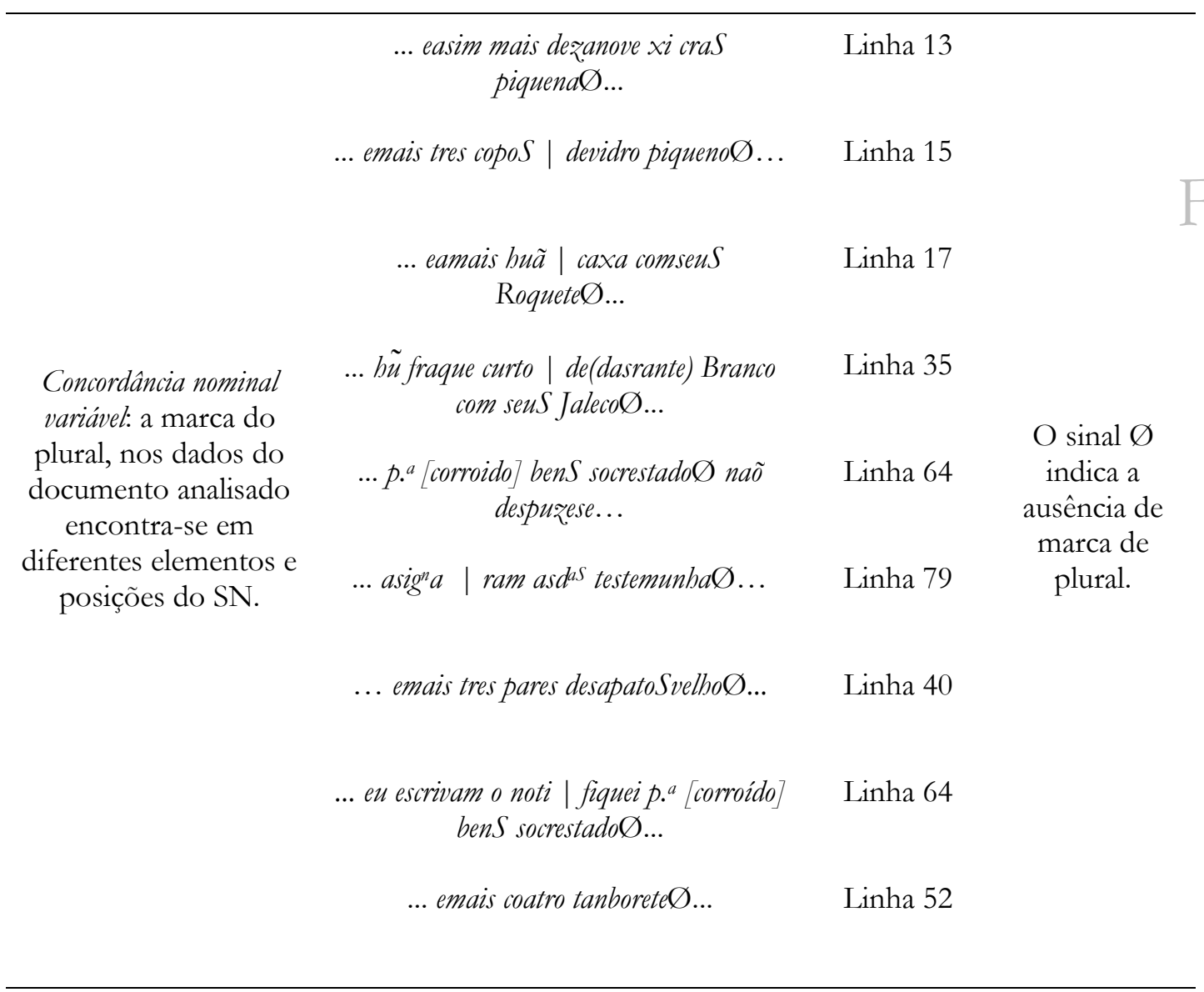




\section{CONSIDERAÇÕES FINAIS}

Segundo Martins (2001), o uso de documentos não-literários como fonte de informação linguística pode produzir resultados tão relevantes no domínio da sintaxe quanto nos da fonologia, da morfologia ou do léxico.

O documento apresentado neste artigo apenas ratifica essa afirmação de que documentos manuscritos não-literários são fontes riquíssimas e inesgotáveis para pesquisa diacrônica. Eles são significativos para história da língua por serem datados e por trazerem registrado o local em que foram exarados. No que diz respeito aos aspectos linguísticos, esses documentos exprimem uma vasta fonte para que se desenvolvam diversas pesquisas no âmbito da Filologia, da Linguística Histórica e da Crítica Textual.

Por evidenciar um uso pretérito da língua portuguesa, contribuindo para o avanço do conhecimento desses estados de língua, os textos antigos assumem também uma grande importância para os estudos diacrônicos. Tendo em vista essa riqueza, a maior parte dos pesquisadores que utilizam documentos manuscritos como corpora de pesquisa devem dar preferência aos textos fidedignos, criteriosamente armazenados segundo normas da edição crítica de textos, conforme se discutiu aqui.

Certamente, os dados aqui apresentados, mesmo que de forma atomística, revelam apenas uma pequena parte do valioso objeto de pesquisa que ora temos em mãos, e muitos outros que ainda se encontram nos arquivos à espera de um estudo.

\section{REFERÊNCIAS}

Bisol L. Harmonização vocálica, uma regra variável [tese]. Rio de Janeiro: Universidade Federal do Rio de Janeiro; 1981.

Cambraia CN, et al. (2001). Cinco breves tratados religiosos alcobacenses: edição semidiplomática (cód. alc. 461). Caligrama - Revista de Estudos Românicos. 2001; 6:7-28. [citado 10 ago. 2018].

Disponível em: http://www.periodicos.letras.ufmg.br/index.php/caligrama/article/view/290/240.

Cambraia CN. Introdução à crítica textual. São Paulo: Martins Fontes; 2005.

Carneiro MLT. Preconceito racial em Portugal e Brasil Colônia: os cristãos-novos e o mito da pureza de sangue. São Paulo: Perspectiva; 2005.

Carvalho DG, Nascimento M. Gramática histórica. 3a ed., São Paulo: Ática; 1969.

Catecismo da Igreja Católica. São Paulo: Loyola/Vozes; 1993.

Constituição Dogmática Lumen Gentium. Documentos do Concílio Ecumênico Vaticano II. São Paulo: Paulus; 1997.

Coutinho I de L. Pontos de gramática histórica. 5a ed. Rio de Janeiro: Livraria Acadêmica; 1962.

Fachin PRM. Descaminhos e dificuldades: leitura de manuscritos do século XVIII. Goiânia: Trilhas Urbanas; 2008.

Mattos e Silva RV. O Português arcaico: Fonologia. São Paulo: Contexto; 1991. 
Martins AM. Emergência e generalização do português escrito: de D. Afonso Henriques a D. Dinis. In: Mira-Mateus MH, organizadora. Caminhos do português. Lisboa: Biblioteca Nacional; 2001. p. 2371.

Mendes ST do P. Combinações lexicais restritas em manuscritos setecentistas de dupla concepção discursiva: escrita e oral [tese]. Belo Horizonte: Faculdade de Letras, Universidade Federal de Minas Gerais; 2008. [citado 10 ago. 2018]. Disponível em: http://poslin.letras.ufmg.br/defesas/479D.pdf.

Spina S. Introdução à edótica. 2ª ed. São Paulo: Edusp/Ars poética; 1994.

Tarallo F. Tempos linguísticos. São Paulo: Ática; 1990.

Villalta LC. A Igreja, a sociedade e o clero. In: Resende MEL de, Villalta LC, organizadores. História de Minas: As Minas setecentistas. Vol. II. Belo Horizonte: Autêntica; Companhia do Tempo; 2007. p. 25-57.

Wernet A. A Igreja paulista no século XIX. São Paulo: Ática; 1987.

Williams EB. Do latim ao português. 6a ed. Rio de Janeiro: Tempo Brasileiro; 1994.

\section{Fonte Manuscrita}

Arquivo Eclesiástico da Arquidiocese de Mariana (AEAM), Minas Gerais. Processo De Genere Vita et Moribus de Francisco de Paula Meireles. Armário 04, pasta 604; 1779. 